\title{
Applied Research on the Design of Signage and Wayfinding System of Historic Blocks from the Perspective of Urban Culture
}

\author{
Xiaoqing $\mathrm{Ma}^{1,}{ }^{*}, \mathrm{Min}^{\mathrm{L}}{ }^{1}$, Jicong Wang ${ }^{1}$, Jia Wang ${ }^{1}$ \\ ${ }^{1}$ Art College, Jiangxi University of Finance and Economics, Nanchang City, Jiangxi Province, 330013, China
}

\begin{abstract}
With the continuous improvement of spiritual and cultural needs, the main reason why people are keen on traveling is that they want to learn about the cultural deposits of the scenic spots. Under this context, this paper takes the signage and wayfinding System of historical blocks as the research object, emphasizes the necessity of extracting urban cultural information and applying it to the signage and wayfinding system design, analyzes the problems existing in the signage and wayfinding system of historical blocks and the application value of urban culture in the signage and wayfinding system of historical blocks. Finally, from the perspective of urban culture, this paper puts forward a suggestion that the design of signage and wayfinding system of historical blocks shall take the characteristics of local buildings, regional styles and folk culture elements as the introduction points.
\end{abstract}

\section{Introduction}

The city records the progress and transitions of human society. As the fundamental element of urban history construction, the historical and cultural blocks are not only the witness of urban development, but also an important aspect to display urban culture. On the premise of meeting the functional needs of urban public residents, the urban historical blocks also play their unique cultural characteristics to undertake the special needs of the public for visiting and sightseeing. As an important part of urban historical blocks, the design quality of signage and wayfinding system directly affects the display of urban historical block culture. A good design shall not only make the signage and wayfinding system contain its own practical functions, but also enable signage and wayfinding system to contain the unique regional characteristics of the city to reflect a certain degree of urban culture.

\section{The necessity of the extraction of Urban Cultural information}

Nowadays, the relationship among different cities is growing closer, and the signage and wayfinding designs applied in cities also tend to be similar and unified. The signage and wayfinding design brings about new problems while conveying information to the public. Signage and wayfinding design starts to shift from difference to unity, indicating that the signage and wayfinding design which highlights the urban culture is gradually decreasing. Therefore, although we visit different urban tourist spots, it seems that all the signage and wayfinding systems we see are the same. In order to make the signage and wayfinding have more regional characteristics, it is necessary to extract the cultural elements of the city, then split, transform, and reorganize them, finally integrate the urban cultural elements into the design and embody them in the signage and wayfinding, so as to emphasize the characteristics of the city and highlight the urban culture. The combination of urban cultural design symbols that conform to the visual image publicity and the signage and wayfinding can directly generate the differentiation competitive advantages among tourist attractions.

\section{Problems existing in the signage and wayfinding system of historical blocks from the perspective of Urban Culture}

\subsection{Deficiency of cultural characteristics and lack of cultural deposits}

Different historical blocks in China have different cultural connotations due to the different historical accumulation of different cities, which makes the cultural deposits contained also different from each other. In the design of the signage and wayfinding system of urban historical blocks, the signage and wayfinding system with cultural elements can be adopted to show its cultural connotations and characteristics. Nowadays, the signage and wayfinding system of the historical blocks tends to pursue the beautiful appearance while ignoring the implication and display of its city culture. For the sake of beautiful visual impression to the public, some historical block signage and wayfinding system even adopts some foreign cultural elements irrelevant to the local culture,

\footnotetext{
*Corresponding author e-mail: 1106420788@qq.com
} 
which makes the signage and wayfinding system in the whole scenic areas lose its local cultural characteristics.

\subsection{Neglect of the coordination of function and form}

At the present stage, the signage and wayfinding of the urban historical blocks in China is gradually showing the trend of homogenization. From the perspective of design, some signage and wayfinding system only focuses on its function, while neglecting the reflection and display of the unique culture of the city, or excessively pursues the innovation of design form while ignoring the function. Therefore, although the characteristics of different historical blocks in different cities vary from each other, most of the signage and wayfinding systems are the same.

\subsection{Lack of systematic planning and design}

To some extent, many cities are deficient in the integrity and systematization of their historical block signage and wayfinding system design, which are mainly embodied in the incongruity between the signage and wayfinding system of the historical and cultural blocks and the surrounding space environment, the mismatching of the styles, the casual distribution of the location and the messy layout. Besides, the unified planning and design are not conducted in the whole system, which is unsystematic.

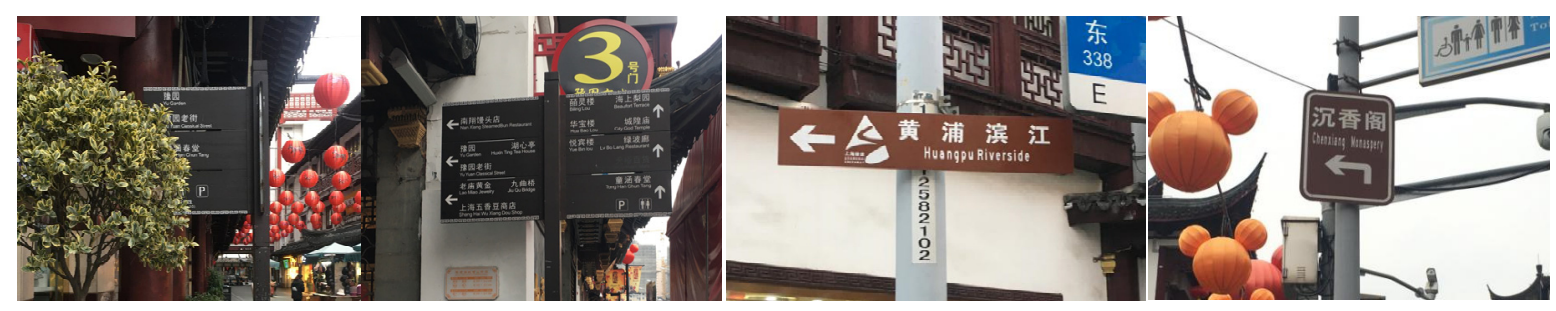

Figure 1. The Random and Unsystematic Layout of Signage and Wayfinding System in Historical Blocks

\section{The application value of Urban Culture in the design of signage and wayfinding system of historical district}

As an important public facility of urban historical blocks, the signage and wayfinding system should not only have its own directive function, but also fully reflect the unique cultural characteristics of the historical blocks, so that the tourists can deeply understand the regional culture of the city while exploring the historical blocks with the help of application of visual symbols in signage and wayfinding system.

\subsection{Social value}

Signage and wayfinding system is generated from society, which depends on the society of existence and serves the society. In return, it promotes the development of the city to a certain degree, which shows the direction, guide the route and direct the public space for the public while performing its practical function, effectively eliminating the feeling of lost of the public in a strange environment. A set of effective signage and wayfinding system can not only improve the affinity of the whole scenic spot and the city, but also improve the visual environment of the city to a certain extent. Through reasonable planning, the signage and wayfinding system of the scenic spot can provide clear instruction services for the public, enable the tourists to arrive at the destination as soon as possible, eliminate the sense of lost in a strange environment to a certain degree and save the time to find the way. For the social public, the establishment of signage and wayfinding system containing urban cultural elements can enhance the awareness of urban culture of the residence, improve their sense of belonging and self-confidence in the city they live in, so as to enhance the cohesion and initiative of the whole city.

\subsection{Cultural value}

Historical block is the fruit of human material civilization and spiritual civilization of a city, which can display and carry on the urban culture well. The rational planning and design of signage and wayfinding system can reflect the cultural deposits and the spirit of the times of a city. An ideal signage and wayfinding system design must contain the cultural connotation of the region where it is located, embody its cultural value, highlight the regional characteristics, meet the functional needs of the public tourists while letting them feel the unique cultural connotation of the region more concretely and thoroughly. The booming tourism promotes the link of China's tourism industry with the world. At the same time, it can spread Chinese culture to every corner of the world. The signage and wayfinding system with urban cultural connotation can help foreign tourists have a preliminary understanding of the culture of the scenic spot, which can then extend to the understanding of the city, thus increasing the attraction and popularity of the city.

\subsection{Aesthetic value}

The signage and wayfinding system of urban historical blocks plays an indispensable role in balancing the environment of the whole scenic spot, which not only has social value and cultural value, but also aesthetic value. Signage and wayfinding system is to exaggerate, transform and use the basic design symbols such as 
points, lines and surfaces, extract the elements that represent the urban culture to integrate appropriately into the design, so that urban culture can be displayed to the public through the signage and wayfinding system. The design of signage and wayfinding system not only adds new vigour and rich colors to the environmental art design of urban historical blocks, but also brings visual beauty to tourists, which can also beautify the urban historical block environment to a certain extent.

\section{The introduction point of the design of signage and wayfinding system of the historical blocks from the perspective of Urban Culture}

\subsection{Introduction from local architectural features}

Gansu is a province with frequent wars in the long history of China. As reflected in the architecture, a large number of military facilities such as city wall and moat, side walls of the Great Wall, passes, beacon towers and so on appeared here, which form the unique architectural characteristics of Gansu. In the ancient town of Jiangnan, the exquisite private gardens can be regarded as the characteristics of local residential buildings, which form its unique garden culture. It can accurately and vividly express the characteristics of this region by means of extracting the most representative architectural characteristics of a region, conducting symbolic design, and applying it to the signage and wayfinding system. Through the reappearance of architectural element symbols on the signage and wayfinding system, visitors can deepen their understanding of a certain regional culture through repeated visual stimulation on the basis of preliminary understanding of a certain urban regional culture, so as to deepen the memory of the whole city, thus enhancing the popularity of the city.

\subsection{Introduction from local colors}

Generally, external information enters the sensory system with vision as the carrier, and the visual response caused by stimulation of color to eyes is the medium. Therefore, compared with text and other information, colors can transmit information to the brain more quickly. It can be said that color is the most lively design language[1]. Different cities have different preferences for colors because of their different history and beliefs. China is rich in urban colors. Jingdezhen, Jiangxi Province, is famous for its blue and white porcelain, Beijing is well-known with its golden glazed tiles and red walls Forbidden City, while the black bricks and dark tiles in the streets and lanes constitute the unique scenery of the ancient towns in the south of the Yangtze River. These places capture the unique and concentrated features of their regional colors, fully reflecting the color characteristics of the city. In the design of the signage and wayfinding system of urban historical blocks, it is necessary to refine the color characteristics best suited to the environment, pay attention to the relationship between the overall unity and partial changes, coordinate the main color with the surrounding environment colors, and change the color in detail partially, which can enrich the colors of the overall signage and wayfinding system, while avoiding the visual fatigue caused by the monotonous color of the whole system. The color design of the signage and wayfinding system of historical blocks should lay emphasis on the sense of rhythm and depth, which should be used in the whole block in a standardized way.

\subsection{Introduction from folk culture elements}

Folk culture is rich and colorful with the characteristics of diversity, covering the area of dialect, food, clothing and so on, which has become a direct manifestation of urban culture. Therefore, it can be used to introduce the design elements in the signage and wayfinding system of urban historical blocks.

Starting from the regional culinary culture: like the Chinese culinary culture, the regional culinary culture in China is gradually established in the constant innovation and inheritance with the changes of society. Due to different ethnic condition, each region has created different regional culinary cultures, such as the earthenware pot soup in Jiangxi, the hot pot in Sichuan and so on. The food culture in different regions shows the unique living habits and national characteristics of people in different regions. Integrating the regional culinary culture into the design of signage and wayfinding system of the urban historical blocks through the way of image can not only enhance the tourists' understanding of the culinary culture of a certain area, but also promote the publicity of the urban culture to a certain extent.

Starting from regional dialects: each region breeds different dialects under the influence of different historical and geographical factors, which has become a significant feature of cultural differences between regions in China. In order to achieve a harmonious social language life, it is necessary to adhere to the following principles: taking Putonghua as the main language, regarding the languages and dialects of all ethnic groups as the auxiliary, and adhering to the standardization while protecting diversity[2]. The application of regional dialects to the design of signage and wayfinding system not only enhances the interest and interaction of signage and wayfinding system, but also publicizes and protects the dialects to a certain extent.

Starting from the folk costumes: as a part of human culture, costume is a social existence that reflects social characteristics. The traditional national folk costume has strong regional characteristics and regional embodiment. Extracting the unique elements of the traditional national folk costume which can represent a certain region, and carrying out symbolic design, and then adopting it in the design of the signage and wayfinding system of the urban historical blocks can reflect the unique personality of the local national culture while enhancing the protection, inheritance, innovation and development of the national folk costumes. For example, the unique women's hat of 
Dali Bai nationality, the Tiger-head shoes for children of Tujia nationality, and the flower-trimmed bonnet of Xinjiang Uygur can be extracted as single directional elements.

\section{Conclusion}

Urban historical block is an important carrier of urban culture display, while the signage and wayfinding system is an indispensable part of urban cultural block. Nowadays, the signage and wayfinding system of urban cultural block is still deficient in the display of culture. How to better protect and inherit the urban regional distinctive culture is of great significance. Therefore, the exploration and continuation of urban cultural resources is particularly important. Based on the perspective of urban regional culture, this paper explores the signage and wayfinding system design of urban historical blocks. On the premise of meeting the functional requirements of the signage and wayfinding system, this paper designs and analyzes from the perspective of urban regional culture, trying to make the urban historical block a tourist place where historical rudiments can be seen everywhere and cultural atmosphere can be experienced at any time.

\section{Reference}

1. Cheng, J.Q. (2012) Research on the application of guiding design in historical and cultural blocks. Northwest University, 15-18.

2. Yuan, Z.R. (2009) Putonghua and dialect with harmonious coexistence, performing their duties and common development (3). Language weekly. 08-07-2009. (001).

3. Du, K.Y. (2018) Research on regional cultural sign design. Changchun Normal University, 9-11.

4. Yang, S., Wen, T.R., Cao, D.M. (2018) Organic renewal of historical blocks guided by cultural creativity: a case study of Tanhualin community in Wuhan. Journal of Huaiyin Institute of technology, 27 (05): 73-78.

5. Gao, K. (2012) Urban public visual guidance sign design from the perspective of urban culture. Qingdao University of science and technology, 35-40.

6. Li, M., Hu, Y. (2012) Research on the design method of urban wayfinding and signage system. New arts, 5: 68-72.

7. Li, M. (2015) Research on the design method of urban public environment wayfinding and signage system - Taking Matsushan City, Japan as an example. New arts, 5: 120-124.

8. Li, M. (2014) Research on the Design of urban public environment wayfinding and signage system. New arts, 7: 109-110. 